\title{
POPULATION GROWTH INDUCED AND HOUSEHOLDS FINANCIAL VULNERABILITY IN NIGERIA
}

\author{
Chidinma C. Mbah ${ }^{1 \mathrm{i}}$, \\ Chike K. Okoli ${ }^{1}$, \\ Chinecherem M. Uzonwanne ${ }^{2}$ \\ ${ }^{1}$ Department of Economics, \\ Nnamdi Azikiwe University, \\ Awka, Anambra State, \\ Nigeria \\ ${ }^{2} \operatorname{Rev} . S r(D r)$, Department of Economics, \\ Nnamdi Azikiwe University, \\ Awka, Anambra State, \\ Nigeria
}

\begin{abstract}
:
Nigeria has been recording a rapid increase in its population over the years. This reality has posed a serious concern for the welfare of households especially as the increase in population growth puts households at the risk of financial vulnerability. Based on this, this study is on the move to examine the impact population growth induced has on household in Nigeria. The study made use of secondary data obtained from World Bank and the Central Bank statistical bulletin spanning from 1981 to 2020 to analyze the impact of population growth induced and its financial vulnerability on household using a structural vector autoregressive model (SVAR). After the analysis, the study found out that in the long run, an increase in financial vulnerability, due to an increase in population growth decreases household welfare in Nigeria. Hence, this study recommends that the Nigerian legislature should formulate a law against rapid population growth induced to ensure that the increase in population does not outscore the means of subsistence.
\end{abstract}

JEL: H10; H31

Keywords: population growth; financial vulnerability; household welfare

\section{Introduction}

One of the major factors contributing to economic hardship in Nigeria is its very large population. Nigeria is the most populous country in Africa and has the seventh-largest population in the world (Nomor, Aor and Orjime, 2019), with a growth rate of about

i Correspondence: email cc.mbah@unizik.edu.ng, cmbahcatherine@gmail.com 
$3.75 \%$ per year. As at the end of 2020, Nigeria's population was estimated to be around 220 million (National Bureau of Statistics, 2020). With current statistics suggesting that the population growth of Nigeria will not slow down soon, the United Nations (2017) predicted Nigeria to become the world's third-largest country by population and one of the six nations with a population of over 300 million by 2050 .

Economic literature associates population growth with negative economic growth implications. Kazeem (2018) states that when population growth outpaces public infrastructure and development by far, then it's a huge red flag. According to Tartiyus, Dauda and Peter (2015), as the global fertility rates continue to outweigh the mortality rate, and currently with almost 7 billion people, the world's natural resources are being placed under a huge strain. This, in turn, gives rise to negative consequences through the different aspects of human life which are being hampered, especially in developing countries. In Nigeria, where most of the households are poor, the continuous growth of the population further increases the incidence of poverty, leading to a decrease in the standard of living (Nomor, Aor and Orjime, 2019). Population growth, therefore, has the likely tendency to increase financial vulnerability of households in Nigeria.

As a matter of fact, the issue of households financial vulnerability is also of growing interest when associated with population in the international literature, especially due to its impact on the economy (Poh-Sabri, 2017). According to the definition of Anderloni, Bacchiocchi and Vandone (2012), financial vulnerability goes together with high indebtedness and other financial problems, as a result of which the households cannot cover their everyday expenses and cannot take care of their future retirement years. Financial vulnerability goes hand in hand with a low standard of living and poor health, as well as households not being able to cope with unexpected financial difficulties (Nemeth, Zsoter and Beres, 2020). These facts suggest that financial vulnerability may be closely linked with the welfare of households. To this end, this study examined the impact population growth has on households in Nigeria with respect to financial vulnerability.

\section{Literature Review}

Nomor, Aor and Orjime (2019) states that population growth is an increase in the number of people that reside in a country, state, county, or city. To determine whether there has been population growth, the following formula is used: (birth rate + immigration) - (death rate + emigration). For the formula, the population growth rate is the rate at which the number of individuals in a population increases in a given period, expressed as a fraction of the initial population. Specifically, population growth rate refers to the change in population over a unit period, often expressed as a percentage of the number of individuals in the population at the beginning of that period. This can be written as the formula, valid for a sufficiently small-time interval:

Population growth rate $=\frac{P\left(t_{1}\right)-P\left(t_{2}\right)}{P\left(t_{1}\right)\left(t_{2}-t_{1}\right)}$ 
A positive growth rate in population indicates that the population is increasing, while a negative growth rate indicates that the population is decreasing. A growth ratio of zero indicates that there was the same number of individuals at the beginning and end of the period- a growth rate may be zero even when there are significant changes in the birth rates, death rates, immigration rates, and age distribution between the two times.

Financial vulnerability is a multi-dimensional concept that relates to risk. Thus, depending on the risk of concern, various disciplines attach different definitions to the concept. In Economics, vulnerability is dealt with both at the micro and macro levels (Naude, Santos-Paulino and McGilivray, 2009). At the micro-level, it is most often referring to the vulnerability to poverty, i.e., the probability that a household or individual will fall into or remain in poverty. This definition depends on one's notion of poverty and how to measure it. Therefore, in practice vulnerability to poverty is measured either as Vulnerability as Expected Poverty (VEP), Vulnerability as Low Expected Utility (VEU) and Vulnerability as Uninsured Exposure to Risk (VER), all regarding the mean and variance of a household's income or consumption (Naude, Santos-Paulino and McGilivray, 2009).

Vulnerability at the macro level is studied in the context that certain hazards may adversely affect a country's economy. These may be natural, like an earthquake or manmade such as a financial crisis. Here it is important to identify and measure the potential occurrence of hazards. From an economic perspective a country's exposure to macroeconomic shocks, such as a financial crisis or sudden drop in export demand, generally depends on its reliance on exports and degree of export diversification, and its openness to financial flows. More specifically, economic vulnerability has been measured in economic literature by a variety of indicators related to a country's foreign trade and investment profile. Various vulnerability indexes on the country level have been proposed since UN-DESA initiated work on the vulnerability of Small Island Developing States (SIDS) in the early 1990s.

Further on the measurement of financial vulnerability, Nemeth, Zsoter and Beres (2020) introduced a new method to measure Financial Vulnerability Index (FVI) based on Organization for Economic Development's financial literacy survey while also analyzing the 2018 OECD survey data along FVI. Their analysis pointed out that although the growth of income reduces financial vulnerability, the higher disposable amount does not increase financial awareness. They found that financially vulnerable population groups not only often struggle to make ends meet, but they also have difficulty controlling spending money.

Acharya, Bhadury, and Surti (2020) also introduced a new financial vulnerability index for emerging market economies by exploiting key differences in their business cycles relative to those of advanced economies. Using the information on the domestic price of risk, cost of dollar hedging and market-based measures of bank vulnerability, their index significantly augmented early warning surveillance capacity, as evidenced by out-of-sample forecasting gains around a majority of turning points in GDP growth, 
relative to distributed lag models hitherto augmented with information from macrofinancial indexes that are custom-built to optimize such forecasts.

Financial vulnerability has become an interesting phenomenon in the international literature, especially due to its impact on the economy (Poh-Sabri, 2017). This, according to Németh, Zsótér, and Luksander (2017) and Poh-Sabri (2017), is due to the financial crisis and its consequences. The research in developing countries associates financial vulnerability mainly with low income (Nemeth, Zsoter and Beres, 2020). Their reasoning is based on the vulnerability caused by poor health, difficult living conditions, and poor social and economic conditions resulting from low income (Lewis and AV Lewis, 2014; Guarcello, Mealli, and Rosati, 2010). This is also occasioned by the fact that financial vulnerability influences financial wellbeing at both individual and household levels. Poh and Sabri (2017) established that high vulnerability is coupled with low income, low liquidity and, often, financial problems, while unemployment is also a typical feature of financially vulnerable individuals.

According to the findings of Finney and Jentzsch (2008), financially vulnerable households faced financial problems more frequently and typically felt that their situation was insoluble. When examining financial vulnerability, Schofield, Percival, Passey, Shrestha, Callander, and Kelly (2010) also emphasize the intensity of financial stress and the lack of ability to cope with it. The research of Al-Mamun and Mazumder (2015) concluded that financial vulnerability and poverty are closely related phenomena. Studies pairing vulnerability and poverty can also be found in the literature. For example, Chiwaula and Waibel (2011) applied research on vulnerability to seasonal data to assess seasonal vulnerability to poverty using panel data from the Hadejia-Nguru Wetlands in Nigeria involving 260 respondents. They found that both observed poverty and vulnerability to poverty vary seasonally and that these variations are related to household livelihood strategies. Mba, Nwosu and Orji (2018) also investigated vulnerability to poverty in Nigeria using the revised General Household Post-harvest survey for Nigeria 2010 and found varying results with respect to regional and household characteristics. Specifically, their findings revealed positive relationships between female-headed households living in the rural area and large household size and household vulnerability. The age of the household head was also found to be significant in influencing household vulnerability to poverty. Mba, Nwosu and Orji (2021) also found that exposure to risks such as job loss, business failure, harvest failure, livestock death, dwelling demolition, increase and decrease in input and output prices, and other similar risks significantly drive households into poverty but differ across households in rural and urban areas, both in characteristics and regions. Other studies on household vulnerability to poverty include Edoumiekumo, Karimo and Tombofa (2013); Adepoju and Okunmadewa and Ozughalu (2014).

Though the majority of the studies on financial vulnerability examined the level of income and vulnerability to poverty, the financial difficulties and problems, as well as the ability/inability to cope with financial difficulties in terms of their relationship with financial vulnerability, the empirical literature is silent on the relationship between population growth household financial vulnerability. Studies closest to this line of 
research considered inequality and household welfare (Oluwatayo, 2009), food price changes and farm household's welfare (Adekunle, Akinbode, Shittu and Momoh, 2020), and access to formal finance and welfare (Adebowale and Ralitza, 2017).

The theoretical link between population growth and households financial vulnerability is expressed by classical economists, notably Malthus and Marx. The theoretical perspective of Malthus is, however, of utmost interest to this study. Malthus predicted starvation (among other positive checks) as an inevitable outcome of sustained population growth. Though he was not specific about what rate of the natural increase in population would lead to this catastrophe, it would appear he believed that any exponential growth rate would suffice. He did, of course, refer to a rate of three per cent in North America as a likely maximum. A fair test would be to accept an annual rate of between two and three per cent as the kind of unchecked population growth that Malthus had in mind (which is about the same rate in Nigeria). In a related prediction, he argued that the improvident poor were encouraged to marry earlier when real wages increased, thus saturating the labour market, thus leading to falling wages and consequent destitution. For Malthus, (a) population growth would outstrip food supplies and result in high mortality unless there is a regime of late marriage which results in negligible population growth, (b) poverty in households is a consequence of excessive fertility caused by improvidence, and (c) poverty in society reflects household poverty in aggregate, with high fertility translating into high rates of natural increase. The Malthusian theory, therefore, suggests that population growth may be responsible for financial vulnerability in Nigeria.

Another theory that forms the basis of this study is the welfare theory. The welfare theory which dates back to Adam Smith in 1776 during his proposition of the concept of the "invisible hand". Smith stated that the individual offers to supply his labour with his advantage in view and not the interest of the society. The modern welfare theory was produced by Pigou (1912) in his distinction between private and social costs. Pigou stated that judicious government can increase welfare through income distribution, which is visible in the payment of wages. To Pigou, welfare rest in the state of mind of man or his consciousness which is made up of his satisfactions or utilities. The hallmark of welfare, therefore, is the extent to which the desires of an individual are met.

Therefore, the theoretical underpinnings of the two theories discussed in this study suggest that population growth and households financial vulnerability may be positively related. This is based on the Malthusian theory's postulation of the negative welfare effects of a highly increasing population. The welfare theory suggests that a household can be classified as welfare-positive only if it can meet its desires. This can be interpreted as having enough income or being able to afford that consumption that guarantees optimal utility. Hence, population-growth-induced could increase or lead to financial vulnerability of households in Nigeria. 


\section{Methodology}

This research is typically analytical in nature. The study made use of secondary data obtained from World Bank and the Central Bank statistical bulletine spanning from 1981 to 2020. The data cover financial vulnerability index (FVI) which is obtained from the CBN, population growth (POPG) which is obtained from the World Bank Statistics, while household welfare (HW) was proxied by household consumption expenditure with the aid of data obtained from the World Bank. The study develops a structural vector autoregressive model (SVAR) to explore how population growth induces households financial vulnerability in Nigeria. The test of stationarity was done using Augmented Dickey-Fuller (ADF) test, while post-estimation tests such as normality test, serial correlation test and test of heteroskedasticity were used to check the reliability of the estimates of the models.

\subsection{Model Specification}

The model used for this study is drawn from the two theories reviewed in the previous section. This study regresses household welfare against financial vulnerability and population growth. The Malthusian theory suggests financial vulnerability as a positive function of population growth. This can be expressed mathematically as follows:

$F V=f(P G R)-$
$F V_{t}=\alpha+\beta P G R_{t}+\varepsilon_{t}$

Where $F V$ is financial vulnerability measured by the financial vulnerability index, and $P G R$ is population growth.

The welfare theory suggests that a household can only meet its consumption needs if it is not financially vulnerable. This implies that household welfare (HW) is a negative function of financial vulnerability (FV). Symbolically,

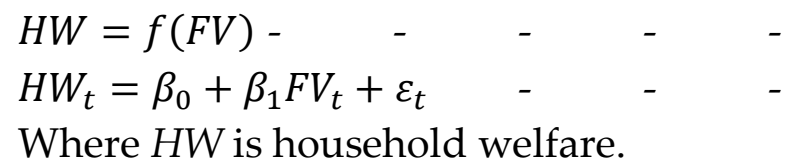

Equations (1) and (3) suggest transmission of the effect of an increase in population growth to household welfare through an induced increase in financial vulnerability. Explicitly, an increase in population growth leads to an increase in financial vulnerability, and the increase in financial vulnerability consequently leads to a fall in household welfare. Symbolically,

$\Uparrow P G R \rightarrow \Uparrow F V \rightarrow \Downarrow H W$

This relationship was estimated using a structural vector autoregressive model (SVAR). SVAR is preferred in this case because of its advantage over standard VAR by 
allowing for the contemporaneous effect of a shock in the real interest rate on agricultural output through the relevant channels. The study identifies population growth by assuming that unexpected variations in population growth are exogenous relative to the coinciding values of the remaining macroeconomic variables included in the SVAR.

Using (4) as optimal lag length according to the lag length criteria reported in section 4, a generic SVAR (4) model can be expressed as:

$A_{0} Y_{t}=A_{1} Y_{t-1}+A_{2} Y_{t-2}+\cdots+A_{4} Y_{t-4}+\varepsilon_{t}$

Where $A_{0}$ is a matrix of contemporaneous coefficients, $A_{1}-A_{4}$ are coefficient matrices at lags $1,2, \ldots, \mathrm{t}$; $Y_{t}$ is the matrix of endogenous variables at current value, and $Y_{t-1}-Y_{t-4}$ are matrices of endogenous variables at lags 1 to 4 .

To capture the contemporaneous effect, the SVAR (4) model can be specified as follows;

$$
\begin{aligned}
& {\left[\begin{array}{ccc}
1 & -\Pi_{12}^{0} & -\Pi_{13}^{0} \\
-\Pi_{21}^{0} & 1 & -\Pi_{23}^{0} \\
-\Pi_{31}^{0} & -\Pi_{32}^{0} & 1
\end{array}\right]\left[\begin{array}{c}
H W_{t} \\
F V_{t} \\
P G R_{t}
\end{array}\right]=\left[\begin{array}{ccc}
\Pi_{11}^{1} & \Pi_{12}^{1} & \Pi_{13}^{1} \\
\Pi_{21}^{1} & \Pi_{22}^{1} & \Pi_{23}^{1} \\
\Pi_{31}^{1} & \Pi_{32}^{1} & \Pi_{33}^{1}
\end{array}\right]\left[\begin{array}{c}
H W_{t-1} \\
F V_{t-1} \\
P G R_{t-1}
\end{array}\right]+} \\
& {\left[\begin{array}{lll}
\Pi_{11}^{2} & \Pi_{12}^{2} & \Pi_{13}^{2} \\
\Pi_{21}^{2} & \Pi_{22}^{2} & \Pi_{23}^{2} \\
\Pi_{31}^{2} & \Pi_{32}^{2} & \Pi_{33}^{2}
\end{array}\right]\left[\begin{array}{c}
H W_{t-2} \\
F V_{t-2} \\
P G R_{t-2}
\end{array}\right]+\left[\begin{array}{c}
\cdots \\
\ddots \\
\ldots
\end{array}\right]+\left[\begin{array}{ccc}
\Pi_{11}^{4} & \Pi_{12}^{4} & \Pi_{13}^{4} \\
\Pi_{21}^{4} & \Pi_{22}^{4} & \Pi_{23}^{4} \\
\Pi_{31}^{4} & \Pi_{32}^{4} & \Pi_{33}^{4}
\end{array}\right]\left[\begin{array}{c}
H W_{t-4} \\
F V_{t-4} \\
P G R_{t-4}
\end{array}\right]+\left[\begin{array}{c}
\varepsilon_{1 t} \\
\varepsilon_{2 t} \\
\varepsilon_{3 t}
\end{array}\right]}
\end{aligned}
$$

Following the recursive approach, which is prominently applied in the empirical literature, $-\Pi_{12}^{0},-\Pi_{13}^{0}$, and $-\Pi_{23}^{0}$ were restricted to zero for the SVAR(4) model to be identified. Thus, the recursive SVAR(4) model is stated below;

$$
\begin{aligned}
& {\left[\begin{array}{ccc}
1 & 0 & 0 \\
-\Pi_{21}^{0} & 1 & 0 \\
-\Pi_{31}^{0} & -\Pi_{32}^{0} & 1
\end{array}\right]\left[\begin{array}{c}
H W_{t} \\
F V_{t} \\
P G R_{t}
\end{array}\right]=\left[\begin{array}{ccc}
\Pi_{11}^{1} & \Pi_{12}^{1} & \Pi_{13}^{1} \\
\Pi_{21}^{1} & \Pi_{22}^{1} & \Pi_{23}^{1} \\
\Pi_{31}^{1} & \Pi_{32}^{1} & \Pi_{33}^{1}
\end{array}\right]\left[\begin{array}{c}
H W_{t-1} \\
F V_{t-1} \\
P G R_{t-1}
\end{array}\right]+\left[\begin{array}{ccc}
\Pi_{11}^{2} & \Pi_{12}^{2} & \Pi_{13}^{2} \\
\Pi_{21}^{2} & \Pi_{22}^{2} & \Pi_{23}^{2} \\
\Pi_{31}^{2} & \Pi_{32}^{2} & \Pi_{33}^{2}
\end{array}\right]\left[\begin{array}{c}
H W_{t-2} \\
F V_{t-2} \\
P G R_{t-2}
\end{array}\right]+} \\
& {\left[\begin{array}{c}
\ddots \\
\cdots
\end{array}\right]+\left[\begin{array}{ccc}
\Pi_{11}^{4} & \Pi_{12}^{4} & \Pi_{13}^{4} \\
\Pi_{21}^{4} & \Pi_{22}^{4} & \Pi_{23}^{4} \\
\Pi_{31}^{4} & \Pi_{32}^{4} & \Pi_{33}^{4}
\end{array}\right]\left[\begin{array}{c}
H W_{t-4} \\
F V_{t-4} \\
P G R_{t-4}
\end{array}\right]+\left[\begin{array}{c}
\varepsilon_{1 t} \\
\varepsilon_{2 t} \\
\varepsilon_{3 t}
\end{array}\right]-}
\end{aligned}
$$

To avoid cross-error correlations or spill-over volatility, and remove the possibility of autocorrelations, we set

$A_{0} Y_{t}=\mathrm{B} U_{t}$

Where $\mathrm{Y}$ is the matrix of endogenous variables, $\mathrm{B}$ is the variance matrix, and $\mathrm{U}$ is the matrix of error terms. This can be presented in matrix form as follows;

$\left[\begin{array}{ccc}1 & 0 & 0 \\ -\Pi_{21}^{0} & 1 & 0 \\ -\Pi_{31}^{0} & -\Pi_{32}^{0} & 1\end{array}\right]\left[\begin{array}{c}H W_{t} \\ F V_{t} \\ P G R_{t}\end{array}\right]=\left[\begin{array}{ccc}\delta_{1} & 0 & 0 \\ 0 & \delta_{2} & 0 \\ 0 & 0 & \delta_{3}\end{array}\right]\left[\begin{array}{l}U_{1 t} \\ U_{2 t} \\ U_{2 t}\end{array}\right]$ 
This implies that

$A_{0} E_{t}=\mathrm{B} U_{t}$

Where $\mathrm{E}$ is the matrix of initial impulses (i.e., initial volatility in the endogenous variables). This can be represented in matrix form as stated in equation 19.

$\left[\begin{array}{ccc}1 & 0 & 0 \\ -\Pi_{21}^{0} & 1 & 0 \\ -\Pi_{31}^{0} & -\Pi_{32}^{0} & 1\end{array}\right]\left[\begin{array}{c}e_{t}^{H W} \\ e_{t}^{F V} \\ e_{t}^{P G R}\end{array}\right]=\left[\begin{array}{ccc}\delta_{1} & 0 & 0 \\ 0 & \delta_{2} & 0 \\ 0 & 0 & \delta_{3}\end{array}\right]\left[\begin{array}{l}U_{1 t} \\ U_{2 t} \\ U_{2 t}\end{array}\right]$

Thus, to compute initial responses, we can set

$E_{t}=A_{0}^{-1} \mathrm{~B} U_{t}$

That is;

$\mathrm{E}=\mathrm{SU}$

Where $S=A_{0}^{-1} B$

This can be presented in matrix form as;

$\left[\begin{array}{c}e_{t}^{H W} \\ e_{t}^{F V} \\ e_{t}^{P G R}\end{array}\right]=\left[\begin{array}{lll}a & 0 & 0 \\ b & c & 0 \\ d & e & f\end{array}\right]\left[\begin{array}{l}U_{1 t} \\ U_{2 t} \\ U_{2 t}\end{array}\right]$

Where,

a = initial response of household welfare to own shock;

$\mathrm{b}=$ initial response of financial vulnerability to shock in household welfare;

$c=$ initial response of financial vulnerability to own shock;

$\mathrm{d}=$ initial response of population growth to shock in household welfare;

$\mathrm{e}=$ initial response of population growth to financial vulnerability shock; and

$\mathrm{f}=$ initial response of population growth to own shock.

\section{Results and Discussions}

\subsection{Stationarity}

The level of stationarity of the series under variables included in this study was analyzed using the Augmented Dickey-Fuller (ADF) test. The ADF test also helps to ascertain if the series have the mean reverting ability and can be used for forecasting the relationship between monetary policy and agricultural development in Nigeria. To achieve a uniform unit of measurement and interpret estimates as percentages, household welfare was 
transformed using log at base 10. The results of the unit root test are presented in Table 1.

Table 1: Unit Root Test

\begin{tabular}{|l|c|c|c|c|c|c|}
\hline Variable & Level ADF & Level Prob & 1 $^{\text {st }}$ Diff ADF & 1 $^{\text {st }}$ Diff Prob & O(I) & Remark \\
\hline LHW & -2.751605 & 0.0750 & $-4.780949^{*}$ & 0.0004 & 1 & Stationary at $1^{\text {st }}$ diff. \\
\hline DLHW & $-4.780949^{*}$ & 0.0004 & - & - & 0 & Stationary at level \\
\hline FV & 1.116681 & 0.9969 & $-3.945280^{*}$ & 0.0044 & 1 & Stationary at $1^{\text {st }}$ diff. \\
\hline DFV & $-3.945280^{*}$ & 0.0044 & - & - & 0 & Stationary at level \\
\hline PGR & $-4.956091^{*}$ & 0.0004 & - & - & 0 & Stationary at level \\
\hline${ }^{*}$ significant at 5\%.
\end{tabular}

Source: Researcher's Computations Using Eviews 10.0.

The unit root results presented in Table 1 reveal mixed order of integration of the series. While household welfare (HW) and financial vulnerability (FV) are integrated of order one, population growth achieved stationarity at level. On the other hand, population growth is stationary at level. This means that household welfare and financial vulnerability have the mean-reverting ability after becoming stationary at the first difference, while population growth has no unit root problem and can produce stable estimates. These are based on the probability values of the ADF statistics at the respective levels of stationarity. Based on the condition for estimating a structural vector autoregressive model concerning the order of integration of series, household welfare and financial vulnerability were re-specified and estimated in their first-difference form.

\subsection{Population Growth, Financial Vulnerability and Household Welfare in Nigeria with the use of Structural VAR}

To conduct forecasts using the structural vector autoregressive model (SVAR) and optimal lag order, the Akaike information criterion (AIC) was adopted for model selection. The typical model selection criteria trade-off the bias associated with a parsimonious parameterization against the inefficiency associated with overparameterization (Thorton, Daniel and Batten, 1985). Results of the SVAR model selection summary are presented in Table 2.

Table 2: SVAR Model Selection Criteria

\begin{tabular}{ccccccc}
\hline \hline Lag & LogL & LR & FPE & AIC & SC & HQ \\
& & & & & \\
& & & & & \\
0 & 133.5203 & NA & $7.37 \mathrm{e}-08$ & -7.910324 & -7.774277 & -7.864548 \\
1 & 186.5533 & 93.20945 & $5.13 \mathrm{e}-09$ & -10.57899 & -10.03480 & -10.39589 \\
2 & 229.2382 & 67.26109 & $6.76 \mathrm{e}-10$ & -12.62050 & $-11.66818^{*}$ & -12.30007 \\
3 & 244.5908 & $21.40061^{*}$ & $4.79 \mathrm{e}-10$ & -13.00550 & -11.64504 & $-12.54775^{*}$ \\
4 & 255.2976 & 12.97785 & $4.66 \mathrm{e}-10^{*}$ & $-13.10894^{*}$ & -11.34034 & -12.51386 \\
5 & 263.5756 & 8.528895 & $5.55 \mathrm{e}-10$ & -13.06519 & -10.88845 & -12.33278 \\
\hline \hline
\end{tabular}

Source: Author's computation using Eviews 10.0. 
Table 2 shows that the Akaike information criterion selected lag 4 for the SVAR model considered in this study. This means that lag 4 is the optimal lag for our model, and thus, our parsimonious model for the analysis of the effect of population growth induced financial vulnerability on household welfare in Nigeria is SVAR(4) model.

\subsection{Structural VAR Estimates}

Table 2: Estimated A Matrix: SVAR Contemporaneous Coefficients

\begin{tabular}{|l|c|c|c|}
\hline & LHW & FV & PGR \\
\hline LHW & 1.000000 & 0.000000 & 0.000000 \\
\hline FV & 0.004955 & 1.000000 & 0.000000 \\
\hline PGR & $-0.006580^{*}$ & -0.052011 & 1.000000 \\
\hline${ }^{*}$ indicates significance at 5\%.
\end{tabular}

Source: Researcher's Computations using Eviews 10.0.

Since theoretically the effect of a shock in one variable is not expected to be immediate on any economic variable, restrictions were recursively imposed on the upper elements of the matrix of contemporaneous effects. The restrictions imposed on the recursive matrix indicate that population growth has no instant effect on financial vulnerability in Nigeria, hence, there is no contemporaneous effect of population growth induced financial vulnerability on household welfare in Nigeria. These effects can only be felt in the long run. However, there is a reverse contemporaneous effect of household welfare on financial vulnerability and household welfare in Nigeria.

Results from the estimated matrix A of the SVAR model indicate that a positive shock in household welfare will have a negative contemporaneous effect on financial vulnerability in Nigeria. This effect is necessitated by the fact that an increase in household welfare suggests an increase in the income and consumption of the household. This increase automatically reduces the chances of the household in question slumping into financial vulnerability. Since financial vulnerability is the likelihood of a household being unable to meet its financial obligations, it suffices to conclude that no household that is welfare-assured is theoretically expected to be vulnerable financially. Results of the estimated matrix A also indicate that population growth will respond positively to instant positive shock in financial vulnerability and household welfare respectively.

A well-to-do household cares less about the increase in its population since the resources to take care of the needs of its members are already available. Wealthy households are known for adopting extended family members and hiring domestic workers. Also, the mortality rate in a welfare household is minimal while the resources available to it catalyze more marriages, hence, increased fertility rate. All these indices are likely to lead to an increase in population growth as a result of an increase in household welfare. Likewise, most households in Nigeria that are financially vulnerable live in rural areas and depend mostly on peasant farming. Even the families in the urban areas that are financially vulnerable depend on petty trading and menial jobs for survival. As a result, household size is an asset to these households. These households believe that more hands are responsible for the increase in productivity and resource availability. As 
a result, when such households become more vulnerable financially, the most likely option is to increase their size through more marriages and increased childbearing. On the other hand, the financial vulnerability affects birth control negatively as vulnerable households lack access to contraceptives and other effective means of family planning. To this end, when financial vulnerability increases in Nigeria, population growth is likely to also increase instantly.

Table 3: Estimated S Matrix: SVAR Short-run Impulse-Responses Coefficients

\begin{tabular}{|l|c|c|c|}
\hline & LHW & FV & PGR \\
\hline LHW & 0.217015 & 0.000000 & 0.000000 \\
\hline FV & -0.001075 & 0.019598 & 0.000000 \\
\hline PGR & 0.001372 & 0.001019 & 0.003159 \\
\hline
\end{tabular}

Source: Researcher's Computations using Eviews 10.0.

The estimated matrix $S$ represents short-run impulse responses of household welfare, financial vulnerability and population growth to short-run shocks in one another respectively. Because the response of household welfare to shock in population growth induced financial vulnerability is only expected in the long run, the theoretical/recursive restrictions applied to the estimated A matrix also apply to the estimated $S$ matrix. In the short run, household welfare, financial vulnerability and population growth in Nigeria will vary positively due to their impulses by $0.22 \%, 0.02 \%$ and $0.003 \%$ respectively. Financial vulnerability will respond negatively to shock in household welfare in the short run while population growth will be positively affected by shocks in household welfare and financial vulnerability in the short run respectively. The nature of these effects is the same as the results of the estimates matrix of contemporaneous effects. The rationales for these responses have also been adequately discussed in the analysis of contemporaneous responses/effects.

Table 4: Estimated F Matrix: SVAR Long-run Impulse-Responses Coefficients

\begin{tabular}{|l|c|c|c|}
\hline & LHW & FV & PGR \\
\hline LHW & 0.179688 & -0.090620 & -0.098266 \\
\hline FV & -0.006173 & 0.030702 & 0.008823 \\
\hline PGR & 0.012600 & 0.107256 & 0.102064 \\
\hline
\end{tabular}

Source: Researcher's Computations using Eviews 10.0.

The long-run impulse responses as shown in the estimated $F$ matrix reveal that, as expected, household welfare will respond to sudden changes in financial vulnerability and population growth in Nigeria in the long run. Since this study is only interested in the effect of financial vulnerability of household welfare as a result of changes in population growth, only the pass-through relationships are analyzed in this subsection. The pass-through relationships are the response of household welfare to impulse in financial vulnerability and the response of financial vulnerability to an impulse in population growth, all in the long run. In addition, responses of the endogenous variables to their own shocks, in the long run, are analyzed. 
The long-run responses of household welfare, financial vulnerability and population growth to their own shocks will cause respective long-run positive increases in themselves by $0.18 \%, 0.03 \%$ and $0.10 \%$. This implies that even if all the factors affecting household welfare, financial vulnerability and population growth are held constant, the macroeconomic variables will naturally increase in the long run.

An impulse in population growth is likely to cause a positive response from financial vulnerability in the long run. If population growth suddenly increases by $1 \%$ in the current period, the financial vulnerability will increase in response by approximately $0.01 \%$ in the long run. This is because when the population growth is high, the rate of growth of the population is likely to outstrip the means of subsistence as discussed in section two in the Malthusian theory of population. An increase in the population of a household leads to an increased cost of living in the household. As a result, the financial vulnerability of the household will likely increase. The increase in population due to shock in population growth makes households vulnerable financially, this also increases the probability of the household being unable to meet its financial obligations in the future.

The increased financial vulnerability due to an increase in population growth will likely transmit into a fall in household welfare in Nigeria in the long run. There will be a $0.09 \%$ decline in household welfare in Nigeria in the long run if financial vulnerability increases by $1 \%$ in the current period. This means that increase in population growth induces financial vulnerability to cause a fall in household welfare in Nigeria in the long run. When financial vulnerability increases, households find it difficult to meet their financial obligations, with their ability to maintain a utility-producing consumption being negatively affected. Thus, the households are no longer able to meet all their needs as stated in the modern welfare theory.

The long-run impulse responses suggest that an increase in population growth will lead to an increase in financial vulnerability which will, in turn, induce a decline in household welfare in Nigeria. This means that population growth induced financial vulnerability has a negative effect on household welfare in Nigeria in the long run.

$\Uparrow P G R \rightarrow \Uparrow F V \rightarrow \Downarrow H W$

\subsection{Generalized SVAR Impulse Responses}

The short and long-run analyses alone do not provide enough evidence to conclude that shock financial vulnerability, induced by population growth, will leave temporary or permanent effects on household welfare in Nigeria. This section, therefore, takes care of this. The impulse response function traces the responses of the endogenous variables from one-time volatility on the current future values of the endogenous variables. The response of financial vulnerability to impulse in the population growth, and the response of household welfare to shock in financial vulnerability are analyzed in this section. 


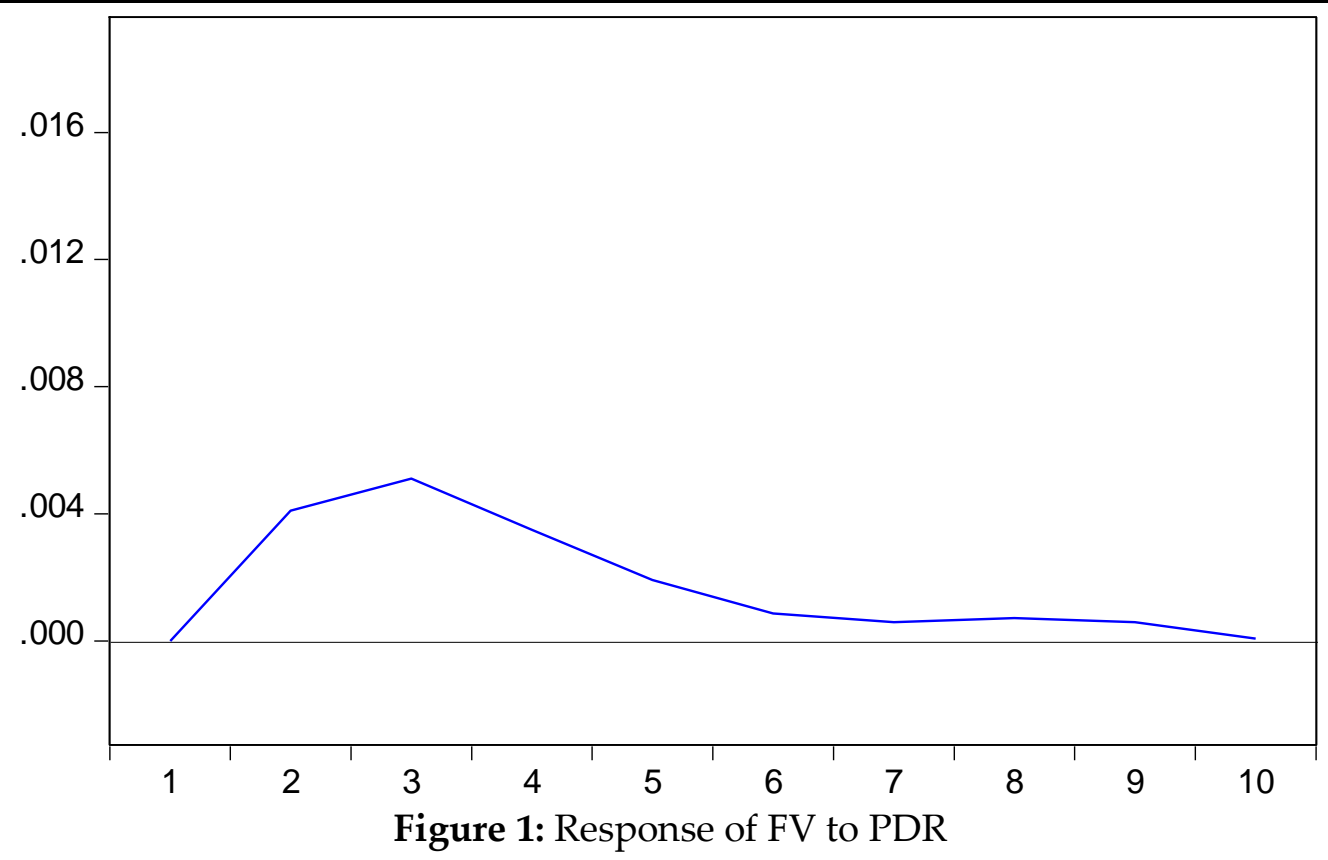

As stated before, a one-time shock in population growth will have a positive effect on financial vulnerability in Nigeria. This effect will be permanent and extend beyond the tenth period. This is because the magnitude of response of financial vulnerability to shock in population growth does not turn to zero even in the tenth period. The magnitude of the effect will, however, be greatest in the third year and decline steadily with time. The non-diminishing effect of a shock in population growth on financial vulnerability in Nigeria is justified by the fact that once the population of a household increases by 1 , the marginal cost of living incurred by the household stays as long as that additional member remains dependent. Even in the circumstance where the additional member of the household becomes independent, there is the likelihood of s/he becoming dependent again as a result of old age.

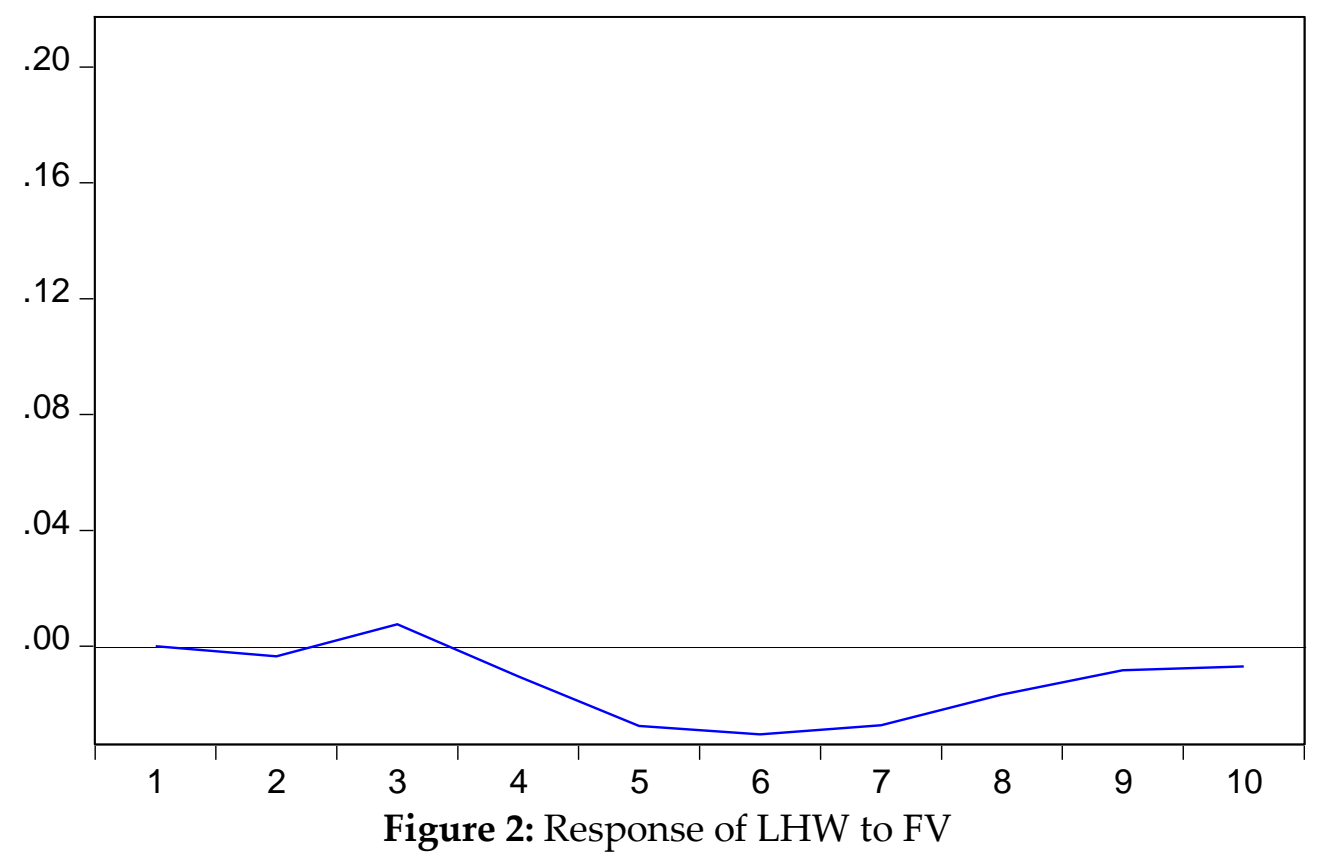


It was established earlier that population growth induces financial vulnerability to cause a decline in household welfare in Nigeria. This negative effect of a positive onetime shock in financial vulnerability, as a consequence of an increase in population growth, on household welfare is permanent as the response line fails to converge to the origin in the tenth period. The permanent effect of financial vulnerability on household welfare in Nigeria is due to the influence of population growth. Since the shock in financial vulnerability considered in this study is the one ascribed to population growth, and population growth leaves a permanent effect on financial vulnerability, populationgrowth-induced financial vulnerability is likely to have a permanent negative effect on household welfare in Nigeria.

\section{Conclusion and Policy Recommendations}

The findings from this study have provided adequate facts upon which conclusions are drawn. The result or the impact of population growth induced and financial vulnerability of households in Nigeria are long-run phenomena. The study has shown that an increase in population growth leads to a permanent rise in financial vulnerability of households in Nigeria. The same increase in population growth induces financial vulnerability to have a permanent negative effect on household welfare in Nigeria. Because population growth, financial vulnerability and household welfare might be characterized by interdependences. It is also good to know that a positive change in household welfare, in the short run, reduces financial vulnerability and raises population growth at the same time. Well-to-do households or households with improved welfare can meet their needs. Such households care less about population growth, leading to a surge in their population.

Going by these conclusions, this study recommends that the Nigerian legislature should formulate a law against rapid population increase to ensure that the rate of increase of the population does not outscore the means of subsistence. Like it is obtainable in other countries like China, the Government should limit the number of children that married couples can have to two. This will not only prevent over-population but also address the risk of financial vulnerability of households and ensure sustainable resource utilization and consumption. The government and non-governmental organizations should embark on massive sensitization of couples on the need for family planning to stop the rapid rate of population growth in Nigeria. In the meantime, the government should sustain the provision of financial support to vulnerable households through conditional cash transfers and soft loans.

\section{Conflict of Interest Statement}

The authors declare no conflicts of interests.

\section{About the Author}

Chidinma C. Mbah is a lecturer in the Department of Economics, Faculty of Social Sciences, Nnamdi Azikiwe University, Awka, Anambra State, Nigeria. She hails from 
Akpo, Aguata Local Government Area, Anambra State, Nigeria. She obtained her B.Sc Economics, M.Sc Economics and PhD (in view) from Chukwuemeka Odumegwu Ojukwu University (formally Anambra State University), Anambra State, Nigeria. She Specializes in Development and International Economics.

Chike K. Okoli is a lecturer in the Department of Economics, Faculty of Social Sciences, Nnamdi Azikiwe University, Awka, Anambra State, Nigeria. He hails from Amaokpala, Orumba North Local Government Area, Anambra State, Nigeria. He obtained his B.Sc Economics from Chukwuemeka Odumegwu Ojukwu University (formally Anambra State University), Anambra State, Nigeria. M.Sc Economics and PhD (in view) from Nnamdi Azikiwe University, Awka, Anambra State Nigeria. He specializes in Development Economics.

Uzonwanne Maria Chinecherem (PhD) is a lecturer in the Department of Economics, Faculty of Social Sciences, Nnamdi Azikiwe University, Awka, Anambra State, Nigeria. She specializes in Development Economics.

\section{References}

Acharya, V. V., Bhadury, S. \& Surti, J. (2020). Financial Vulnerability and RiSsks to Growth in Emerging Markets. NBER Working Paper No. 27411, http://www.nber.org/papers/w27411

Adebowale, O. \& Ralitza, D. (2017). Does access to formal finance matter for welfare and inequality? Micro level evidence from Nigeria. GDI Working Paper 2017-007. Manchester: The University of Manchester.

Adekunle, C. P., Akinbode, S. O. Shittu, A. M. \& Momoh, S. (2020). Food price changes and farm households' welfare in Nigeria: Direct and indirect approach. Journal of Applied Economics, 23(1), 409-425, DOI: 10.1080/15140326.2020.1743103

Adepoju, A. O. \& Okunmadewa, F. Y. (n.d). Households' vulnerability to poverty in Ibadan metropolis, Oyo State, Nigeria. Journal of Rural Economics and Development, 20(1), 44-57

Al-Mamun, A. \& Mazumder, M. N. H. (2015). Impact of microcredit on income, poverty, and economic vulnerability in Peninsular Malaysia. Development in Practice, 25(3), 333-346, https://doi.org/10.1080/09614524.2015.1019339

Chiwaula, L. \& Waibel, H. (2011). Does seasonal vulnerability to poverty matter? A case study from the Hadejia-Nguru Wetlands in Nigeria. Proceedings of the German Development Economics Conference, Berlin 2011, No. 19, ZBW - Deutsche Zentralbibliothek für Wirtschaftswissenschaften, Leibniz-Informationszentrum Wirtschaft, Kiel und Hamburg

Edoumiekumo, S. G., Karimo, T. M. \& Tombofa, S. S. (2013). Determinants of Households' Poverty and Vulnerability in Bayelsa State of Nigeria. International Journal of Humanities and Social Science Invention, 2(12), 14-23 
Finney, A. \& Jentzsch, N. (2008). Consumer Financial Vulnerability: Technical Report. European Credit Research, 1-52

Guarcello, L., Mealli, F. \& Rosati, F. C. (2010). Household vulnerability and child labor: the effect of shocks, credit rationing, and insurance. Journal of Population Economics, 23(1), 169-198, https://doi.org/10.1007/s00148-008-0233-4

Mba, P. N., Nwosu, E. O. \& Orji, A. (2018). An Empirical Analysis of Vulnerability to Poverty in Nigeria: Do Household and Regional Characteristics Matter? International Journal of Economics and Financial Issues, 8(4), 271-276.

Mba, P. N., Nwosu, E. O. \& Orji, A. (2021). Effects of Exposure to Risks on Household Vulnerability in Developing Countries: A New Evidence from Urban and Rural Areas of Nigeria. SAGE Open January-March 2021, 1-11 DOI: $10.1177 / 21582440211002214$

Naudé, W., Santos-Paulino, A. U. \& McGillivray, M. (2009). Vulnerability in developing countries. WIDER Angle newsletter, September 2009.

Németh, E., Zsótér, B. \& Luksander, A. (2017). A 18-35 évesek pénzügyi kultúrája - a pénzügyi sérülékenység háttértényezői. (Financial Literacy of Youth Between 1835: Background Factors of Financial Vulnerability.) Esély, 2017(3), 3-34

Oluwatayo, I. B. (2009). Explaining Inequality and Welfare Status of Households in Rural Nigeria: Evidence from Ekiti State. Academic Journal of Plant Sciences, 2 (1), 29-38

Poh, L. M. \& Sabri, M. F. (2017). Review of Financial Vulnerability Studies. Archives of Business Research, 5 (2), 127-134

Schofield, D. J., Percival, R., Passey, M. E., Shrestha, R. N., Callander, E. J. \& Kelly, S. J. (2010). The financial vulnerability of individuals with diabetes. The British Journal of Diabetes and Vascular Disease, 10(6), 300-304, https://doi.org/10.1177/1474651410385864 
Creative Commons licensing terms

Authors will retain copyright to their published articles agreeing that a Creative Commons Attribution 4.0 International License (CC BY 4.0) terms will be applied to their work. Under the terms of this license, no permission is required from the author(s) or publisher for members of the community to copy, distribute, transmit or adapt the article content, providing a proper, prominent and unambiguous attribution to the authors in a manner that makes clear that the materials are being reused under permission of a Creative Commons License. Views, opinions and conclusions expressed in this research article are views, opinions and conclusions of the author(s). Open Access Publishing Group and European Journal of Economic and Financial Research shall not be responsible or answerable for any loss, damage or liability caused in relation to/arising out of conflict of interests, copyright violations and inappropriate or inaccurate use of any kind content related or integrated on the research work. All the published works are meeting the Open Access Publishing requirements and can be freely accessed, shared, modified, distributed and used in educational, commercial and non-commercial purposes under a Creative Commons Attribution 4.0 International License (CC BY 4.0). 